\title{
Des primes plus basses pour vous et vos collaborateurs
}

Connaissez-vous les contrats-cadres FMH Insurance Services pour l'assurance accident obligatoire (LAA) et l'assurance maladie perte de gain (LCA) ? Membres de FMH Services bénéficient de conditions particulièrement attractives dans ce domaine. C'est avec plaisir que nous vous soumettons des offres comparatives sans frais ni engagement adaptées à vos besoins et vous démontrons ainsi votre potentiel d'épargne. Faites appel à notre proposition afin de vous permettre ainsi qu'à vos collaborateurs d'économiser des primes.

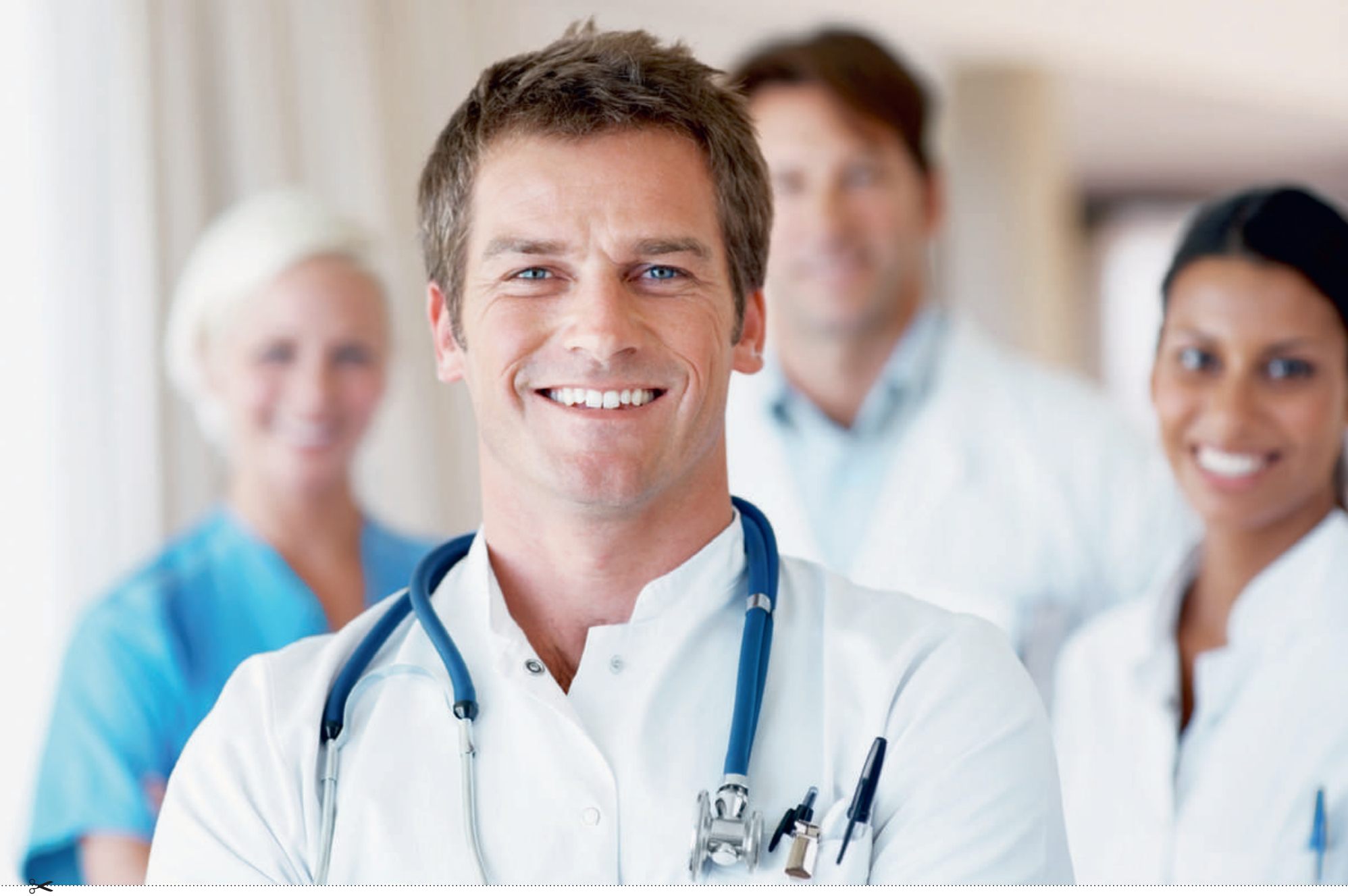

- Mes collaborateurs et moi désirons faire des économies sur les primes. Veuillez vérifier mes assurances personnelles et m'envoyer une offre comparative. (Veuillez annexer une copie de votre police d'assurance actuelle).

$\square \quad$ Veuillez m'appeler pour un conseil personnalisé

Prénom / Nom

Adresse

NPA / Lieu

Téléphone privé / cabinet

Atteignable le plus facilement

Adresse E-Mail

Talon réponse: prière d'envoyer ou de faxer au 0319595010

\section{GMH INSURANCE}

Roth Gygax \& Partner AG घ Koordinationsstelle Moosstrasse 2 a 3073 Gümligen

Téléphone 0319595000 - Fax 0319595010

mail@fmhinsurance.ch —www.fmhinsurance.ch 